\title{
Maracatu do Baque Virado: Da extensão ao diálogo ${ }^{1}$
}

\author{
Maracatu do Baque Virado: De la extensión al diálogo \\ Maracatu do Baque Virado: From extension to dialogue
}

\author{
Carlos Eduardo Amaral de Paiva \\ Jessica Helena Silva ${ }^{3}$
}

\begin{abstract}
Resumo
Este artigo relata o projeto de extensão Ritmos e Elementos do Maracatu de Baque Virado, desenvolvido na Universidade Federal de Alfenas. A partir da condição de coordenador do projeto e discente extensionista realizamos uma observação participativa e a comparação da prática do Maracatu dentro da Universidade com outros grupos tradicionais. Com isso buscamos problematizar a relação da universidade com as práticas da cultura popular, enfatizando as formas de organização, a transmissão dos saberes e a relação entre a cultura acadêmica e a cultura popular. Chegamos à conclusão que a prática de uma cultura popular dentro da universidade pode se configurar como um importante passo na democratização do espaço acadêmico não apenas no sentido de acesso, mas principalmente no sentido de convivência de diferentes organizações e práticas culturais.
\end{abstract}

Palavras-Chave: Maracatu, extensão, cultura popular.

\section{Resumen}

Este artículo relata el proyecto de extensión Ritmos y Elementos del Maracatu de Baque Virado, desarrollado en la Universidad Federal de Alfenas en los años 2016/2017. A partir de la condición de coordinador del proyecto y discente extensionista realizamos una observación participativa y la comparación de la práctica del Maracatu dentro de la Universidad con otros grupos tradicionales. Con ello buscamos problematizar la relación de la universidad con las prácticas de la cultura popular, enfatizando las formas de organización, la transmisión de los saberes y la relación entre la cultura académica y la cultura popular. Llegamos a la conclusión de que la práctica de una cultura popular dentro de la universidad puede configurarse como un paso importante en la democratización del espacio académico no sólo en el sentido del acceso, sino principalmente en el sentido de convivencia de diferentes organizaciones y prácticas culturales.

Palabras claves: Maracatu do Baque Virado, extensión, cultura popular.

\footnotetext{
${ }^{1}$ Artigo apresentado no Simpósio Temático 7 (Experiências Estética com a arte enquanto cultura) durante o II Seminário Latino-Americano de Estudos em Cultura - SEMLACult em Foz do Iguaçu/PR, Brasil, 2018.

2 (Doutor em Sociologia; professor do Instituto de Ciências Humanas e Sociais da UFMT; Cuiabá, MT, Brasil; epaiva.ufmt@gmail.com )

${ }^{3}$ (Bacharel em História, professora da E.M. Cônego Arthur Campestre, Campestre, MG, Brasil; jessicahelena.cp@gmail.com )
} 


\begin{abstract}
This article reports the extension project Rhythms and Elements of the "Maracatu do Baque Virado", developed at the Federal University of Alfenas. From the condition of project coordinator and extension student we made a participatory observation and the comparison of Maracatu practice within the University with other traditional groups. With this, we seek to problematize the relationship between the University and the practices of popular culture, emphasizing the forms of organization, the transmission of knowledge and the relationship between academic culture and popular culture. We came to the conclusion that the practice of a popular culture within the university can be configured as an important step in the democratization of academic space not only in the sense of access, but mainly in the sense of coexistence of different cultural organizations and practices.
\end{abstract}

Keywords: Maracatu do Baque Virado, extension, popular culture.

\title{
1.Introdução
}

Este artigo busca relatar a experiência do projeto de extensão "Ritmos e elementos do maracatu de Baque Virado" desenvolvido no ano de 2017 na Universidade Federal de Alfenas (UNIFAL) pelo grupo Muiraquitã. Com isso, buscamos refletir como a prática do maracatu dentro dos muros da universidade pode apresentar a incorporação de novos saberes, bem como estabelecer importantes formas de sociabilidade entre os extensionistas, a comunidade universitária e a comunidade externa.

O artigo-relato também focará na prática da extensão como diálogo constante e fundamental na construção de uma universidade pública democrática. Pensamos a democratização da universidade não apenas como acesso ao saber acadêmico, mas também como democratização epistemológica, no sentido de construção e respeito a novos saberes advindos de outras culturas não acadêmicas/eruditas.

Nesta perspectiva estabelecemos algumas questões: qual a relação construída historicamente entre a cultura popular e o saber universitário? As transformações da sociedade no século XXI e a crise de legitimidade pela qual passa o saber universitário transformam estas relações? As práticas culturais populares podem contribuir para a transformação da universidade? Estas práticas sofrem mudanças dentro do contexto acadêmico? Qual o papel da extensão para o desenvolvimento de uma vocação democrática da universidade?

Paulo Freire (1983), ao investigar a ideia de extensão, chama atenção para o caráter antidialógico que o significado da palavra pode tomar. Extensão, que deriva do verbo estender, possui uma conotação de "estender algo há alguém". Tal prática não leva em conta os saberes da comunidade, que neste contexto é tratada como objeto do extensionista. Para 
uma verdadeira democratização da universidade, Freire sugere que a ideia de extensão seja substituída por comunicação, ou seja, uma relação dialógica de troca entre o universitário extensionista com a comunidade, onde o saber de um complementa de maneira dialógica o saber do outro. A perspectiva comunicacional de Paulo Freire permite compreender o papel da multiplicidade epistemológica para o avanço de formas democráticas na organização universitária.

Devemos partir da perspectiva que comunicação não significa apenas transmissão, a ideia de comunicar engloba transmissão, recepção e resposta. Assim, ao assinalar o caráter comunicativo da extensão partimos do princípio que esta desenvolve práticas dialógicas tanto dentro da universidade quanto em sua relação com a comunidade externa.

Por meio da análise qualitativa almejamos expor as principais concepções da prática do Maracatu do Baque Virado pelo grupo Muiraquitã. A observação participativa das oficinas e apresentações do grupo nos permite traçar um pequeno itinerário das práticas culturais do grupo e sua forma de organização, bem como estabelecer um estudo comparativo entre o maracatu de baque virado praticado dentro dos muros da universidade e outros grupos, principalmente os tradicionais, conhecidos como nações ${ }^{4}$.

Uma crítica muito comum sobre a prática de Maracatu de Baque Virado dentro da universidade se refere aos perigos da burocratização advindos do próprio formato da instituição universitária. Afirma-se que ao transformar a prática do maracatu em um projeto de extensão, esta manifestação cultural corre o risco de perder sua "espontaneidade" e se descolar cada vez mais de seu caráter popular. Muito embora esta crítica seja legítima, nossa abordagem buscou demonstrar que, no caso da UNIFAL, o maracatu como prática de cultura popular não se burocratizou, ao contrário, conseguiu utilizar os recursos advindos da estrutura universitária se reinventando e se fortalecendo enquanto grupo.

A observação participativa nos permite analisar que no caminho oposto do enrijecimento acadêmico, o maracatu permitiu uma abertura para novos saberes e novas concepções culturais dentro da academia. Ao se tornar um dos projetos de extensão com maior visibilidade dentro da Universidade Federal de Alfenas, o projeto de extensão "Ritmos

\footnotetext{
${ }^{4}$ Nação é o título que recebe os grupos tradicionais do Maracatu de Baque Virado, em relação aos grupos percussivos que surgiram pelo Brasil e o mundo entre os fins da década de 1980 e início da década de 1990. Essa diferenciação é utilizada não apenas como forma de demarcação entre uma prática de um e outro, seja pela ligação com terreiros de matriz africana, seja pela ancestralidade comum invocada, mas, sobretudo, como forma de conferir legitimidade dos primeiros em relação aos demais.
} 
e Elementos do Maracatu do Baque Virado”, vem transformando algumas concepções sobre o saber acadêmico.

O método comparativo, por sua vez, busca enriquecer a análise sobre as diferentes formas de sociabilidade engendradas nos diferentes contextos do maracatu de baque virado. Se em algumas nações do maracatu o fortalecimento da tradição se encontra como eixo central desta prática, no caso do grupo de extensionistas, as constantes pesquisas, reflexões e críticas auxiliam na formação de diferentes perspectivas sobre o que é maracatu. Observa-se que embora haja um respeito pela tradição e religiosidade desta prática, existe também uma reflexão sobre o que é o maracatu e consequentemente uma ampliação do campo desta manifestação.

\section{O maracatu e o muiraquitã: algumas práticas e formas organizativas}

O maracatu é uma prática cultural surgida em Pernambuco, produto histórico das coroações de reis negros das Irmandades Católicas dos Homens Pretos e dos reis de Congo. Uma manifestação do período colonial que se manteve principalmente na cidade de Recife por meio das chamadas nações de maracatu. Importantes pesquisadores brasileiros como Pereira da Costa, Mário de Andrade, Oneyda Alvarenga e Guerra Peixe estudaram esta manifestação e buscaram apontar para a manutenção de uma tradição do maracatu que vem desde o período colonial.

Assim como tantas outras práticas afrodescendentes, o maracatu sofreu perseguição e repressão policial. A própria palavra maracatu, genericamente, significava qualquer agrupamento de negros em festas, batuques e candomblés. Com a transformação do folguedo em objeto de estudos dos folcloristas, em meados dos anos 1930, esta prática passa a ter relativo prestígio, o que não significou, contudo, que as práticas mágico-religiosas gozassem desta mesma sorte e, como a relação do maracatu com a religiosidade afro-brasileira sempre fora intrínseca, o olhar cuidadoso e temeroso das autoridades policias nunca deixou de existir. Durante boa parte do século XX, o maracatu manteve-se classificado como manifestação folclórica do povo pernambucano. Se no âmbito oficial esta manifestação foi catalogada e tratada como folclore, portanto, como uma cultura em extinção que deve ser protegida, no cotidiano o maracatu é uma prática cultural religiosa e carnavalesca, junção do sagrado com o profano. Uma manifestação dinâmica, pulsante e viva, muito diferente da fragilidade estática e primitiva como buscam catalogar os folcloristas. 
Esta vitalidade foi sentida a partir de fins dos anos 1980 e início de 1990 com o chamado boom do Maracatu. O surgimento do movimento mangue beat e o manifesto "Caranguejo com Cérebro" ressignificaram a prática do maracatu assimilando o rock e hiphop aos baques, guitarras às alfaias e letras politizadas às loas ${ }^{5}$. O surgimento de artistas e grupos como Chico Sciense e Nação Zumbi, Mundo Livre S.A, Banda Eddie, dentre outros deram visibilidade nacional e internacional a esta manifestação.

É importante destacar que o movimento Mangue Beat trouxe também um discurso crítico dentro do próprio maracatu. A publicação do manifesto "Caranguejos com Cérebro" foi um marco na discussão sobre as manifestações populares da periferia de Recife, bem como uma denúncia da estratificação social urbana.

Foi justamente esta "modernização" por meio das mídias que permitiu um fortalecimento da tradição das nações de maracatu. Como se sabe, os movimentos de modernização são ambíguos, se por um lado o mangue beat ofereceu uma visibilidade ao movimento, por outro, ofereceu um importante mote para o fortalecimento das nações mais vinculadas à tradição do maracatu. Resistência, religiosidade e raízes tornaram-se palavras chaves para a invenção de tradições em contraposição à modernização mercadológica dos novos astros do maracatu atômico.

Outro fator de grande relevância para a disseminação de novos grupos Brasil e mundo afora, foi a configuração do Maracatu Nação Pernambuco. A pesquisadora Jailma Oliveira assinala que esta configuração alcançou "relativo sucesso, dando origem ao que se convencionou chamar de grupos percussivos" (OLIVEIRA, 2011, p.26).

Neste movimento de modernização-tradição observa-se uma expansão da prática do maracatu. A prática, que até então se limitava ao estado de Pernambuco, passou a ganhar novos espaços e novos atores. Neste novo cenário o maracatu ganhou a adesão de jovens estudantes universitários das classes médias. Embora haja um respeito pela tradição religiosa, na maioria dos casos estes grupos não se atêm aos aspectos sagrados do maracatu, dando uma maior ênfase a musicalidade e a performance.

É neste contexto que surge, em 2004, o grupo Muiraquitã de Maracatu do Baque Virado na Escola de Farmácia e Odontologia de Alfenas (EFOA), que viria a se tornar a Universidade Federal de Alfenas (UNIFAL) em 2005.

No ano de 2006 o grupo torna-se o projeto de extensão "Ritmos e elementos do Maracatu de Baque Virado" investindo em ações na cidade de Alfenas e investigações

\footnotetext{
${ }^{5}$ Loas são os versos das canções executadas nas diferentes nações de maracatu.
} 
práticas e teóricas. Muito embora o Muiraquitã se alinhe aos demais grupos e nações de maracatu de baque virado, existem algumas distinções em sua forma organizativa, bem como na prática cultural. Estas diferenças são advindas da própria estrutura do projeto de extensão no contexto universitário. Como demonstraremos neste artigo, estas diferenças podem enriquecer tanto a prática do maracatu quanto a própria concepção de ensino-aprendizagem e saber dentro da universidade.

Uma diferença que marca a identidade do grupo se refere à periodicidade. Por se tratar de um grupo de discentes o projeto segue o calendário acadêmico, assim, o carnaval não representa para o grupo um período de intensas atividades tal como ocorre com os grupos tradicionais de Recife. Em compensação o grupo se apresenta em diversas datas do ano participando de importantes festas e eventos na cidade de Alfenas e região. A participação constante em eventos fora dos muros da universidade cria laços afetivos com a comunidade alfenense, assim, embora o grupo seja formado por extensionistas de fora da cidade de Alfenas, o envolvimento cultural com a cidade é capaz de criar laços de solidariedade entre os universitários e a cidade.

Tal perspectiva é fundamental no processo de democratização da universidade, o modelo altamente burocratizado e voltado para máxima eficiência da produção do saber acaba, muitas vezes, afastando a universidade da comunidade. A prática de uma cultura não erudita e fora dos muros da universidade se apresenta como uma forma bastante útil na construção de uma verdadeira comunicação com a comunidade.

A participação feminina no grupo Muiraquitã também deve ser destacada como marca de sua singularidade em comparação com outros grupos. Como se sabe, em grupos tradicionais de maracatu, antes do período conhecido como boom do maracatu, às mulheres estavam reservadas apenas as funções dos bastidores do folguedo, como a costura, a confecção de adereços, o preparo de comidas ou, ainda, na participação da corte real, na representação das figuras femininas. Com as mudanças ocorridas após os anos 1990, as mulheres começam a ter um maior prestígio e participação na bateria do corpo percussivo, porém, ainda existe uma restrição na execução de alguns instrumentos, principalmente no toque de alfaias e atabaques - nos grupos em que este instrumento é utilizado (SILVA, 2017).

Entre os grupos percussivos surgidos na referida década, há aqueles que ainda mantém as mesmas restrições impostas pelas nações e há aqueles que operam por lógicas distintas. Ora, o grupo Muiraquitã é formado por uma participação expressiva de mulheres, sendo inclusive regido por uma, e tendo duas regências femininas anteriores. 
Esta participação feminina não é fruto do acaso, ela é refletida constantemente pelas integrantes e possui um caráter político. O grupo é presença constante em diversos eventos que pautam a discussão feminista, tanto dentro da UNIFAL quanto na cidade de Alfenas.

Esta participação feminina no folguedo, além de representar um agenciamento feminino dentro do maracatu, é expressiva de uma prática reflexiva e contestatória da própria cultura popular. Ao dar uma expressividade feminina a uma manifestação cultural que até pouco tempo atrás era restrita ao mundo masculino, as participantes do projeto politizam a cultura e participam do próprio movimento de transformação da cultura popular. Afinal, se é verdade que a cultura popular pode reproduzir práticas da sociedade patriarcal masculina, também é verdade que, uma vez que as práticas culturais são vivenciadas no cotidiano, são dinâmicas e transformativas. Podem representar a resignação, mas podem também articular uma resistência.

Outra diferença significativa se refere à permanência intermitente dos participantes. Dado o caráter de projeto de extensão vinculado à universidade o grupo possui uma grande rotatividade de integrantes. Não possuindo uma estabilidade característica de outros grupos, o Maracatu Muiraquitã desenvolveu estratégias dinâmicas para manutenção de sua coesão. A rotina de ensaios consegue dar conta de investigação e experimento de diversos tipos de baques virados, e o compromisso de alguns membros acaba por formar uma estrutura de ensino horizontal, onde os membros antigos passam os baques aos novos integrantes do grupo. Ainda que exista uma regente responsável pelo andamento dos ensaios, o processo de aprendizagem é descentralizado, os integrantes que adquirem habilidades em determinado instrumento tornam-se responsáveis por passar seu conhecimento adiante.

Esta pedagogia descentralizada se afasta das hierarquias de alguns grupos tradicionais do maracatu. Afasta-se também do modelo hierárquico de produção de conhecimento dentro da universidade. A descentralização do ensino-aprendizagem, o compartilhamento de saberes e a responsabilização horizontal representam formas solidarias e democráticas de transmissão do saber.

A partir das comparações sobre as formas organizativas do grupo Muiraquitã podemos estabelecer agora qual o significado destas transformações para o próprio grupo e para a universidade. O modelo organizativo do grupo e as formas de transmissão de conhecimento apresentam um modo de educação próprio que está intimamente associado à prática da cultura popular, como demonstra Brandão: 
Os movimentos de cultura popular partem do princípio de que o trabalho de transformar e significar o mundo é o mesmo que transforma e significa o homem e a mulher. Como uma prática sempre coletiva e socialmente significativa, o ser humano se realiza através de ações culturalmente tidas como necessárias e motivadas. Assim, a própria sociedade, em que o homem e a mulher se convertem em um ser humano, é parte da/s cultura/s, no sentido mais amplo que se possa atribuir a esta palavra. Também a consciência do homem e da mulher - como aquilo que permite a eles não apenas conhecer, como os animais, mas conhecer-se conhecendo, e que lhe faculta transcender simbolicamente o mundo da natureza de que é parte e sobre o qual age - é uma construção social, que constitui e realiza o trabalho humano de agir sobre o mundo, enquanto age significativamente sobre si mesmo. (BRANDÃO, 2006,p.95)

Dentro da tradição das Ciências Sociais a cultura popular foi, por muito tempo, vista como primitiva ou pré-reflexiva, adjetivos como espontâneo, emotivo ou irracional fazem parte das formas de classificação das culturas populares. A perspectiva assinalada por Carlos Rodrigues Brandao nos auxilia a compreender esta prática como atividade de reflexão e mediação do homem com a natureza na construção de si.

Destarte, o maracatu de baque virado como projeto de extensão permite uma reflexão sobre a cultura popular e sobre o próprio sistema de ensino universitário. $\mathrm{O}$ encontro do saber acadêmico com uma experiência da cultura popular pode se apresentar como um espaço privilegiado para abordarmos o entrecruzamento de diferentes concepções de aprendizagem e epistemologias como discutiremos agora.

\section{Cultura como distinção versus cultura como integração.}

Ao analisar o sistema de ensino francês o sociólogo Pierre Bourdieu (1974) assinala que este forma um verdadeiro sistema de organização do pensamento. Para o autor a cultura não é apenas um código comum de respostas a um problema, mas um conjunto de esquemas previamente assimilados, ou seja, a cultura é uma forma de classificação que exprime realidades coletivas.

Enquanto força "formadora de hábitos, a escola proporciona aos que se encontram direta ou indiretamente submetidos à sua influência, não tanto esquemas de pensamento particulares e particularizados, mas uma disposição geral geradora de esquemas particulares capazes de serem aplicados em campos diferentes do pensamento e da ação aos quais se pode dar o nome de habitus cultivado. (BOURDIEU, 1974,p.211)

Para Bourdieu a escola é uma instância de transmissão de uma cultura legitimada pela classe dominante. Segue logicamente que o ato de transmissão cultural implica na afirmação 
do valor desta cultura transmitida e a desvalorização implícita ou explicita de outras possibilidades de cultura. (BOURDIEU, 1974,p.218)

Assim, ao perder a função de unificar, a cultura torna-se distintiva e marca de estratificação entre as classes sociais. A escola cumpre a função de consagrar esta distinção, mas vai além, ela dispõe de um sistema de categorias de percepção, de linguagem, de pensamento e de apreciação que embora se camuflem como universais, são valores das classes dominantes. A análise de Bourdieu permite um questionamento do currículo e dos métodos pedagógicos, e torna-se ainda mais incisiva ao observamos o modelo ensinoaprendizagem desenvolvidos em âmbito acadêmico.

Entretanto, Bourdieu observa as culturas populares pela ótica da resignação. Para o autor, a arte popular é a arte das classes médias e subalternas desprovidas de um capital cultural, essas manifestações artísticas são guiadas pela funcionalidade ou pragmatismo que condenam os indivíduos das classes trabalhadoras a um gosto simples e modesto, em oposição à cultura desinteressada das classes dominantes.

$\mathrm{Na}$ interpretação de Bourdieu a cultura popular não possui um esquema organizado capaz de se objetivar e tampouco pode formar-se como um sistema de pensamento capaz de disputar espaço com a cultura erudita hegemônica e legitimada pela escola. Bourdieu tem razão ao assinalar a subalternidade da cultura popular, entretanto sua perspectiva reprodutivista acaba não levando em consideração as diferentes formas organizativas das culturas não burguesas, que embora encontrem obstáculos para sistematização e objetivação, constroem estratégias de ocupação do espaço público diferentes das estratégias das culturas institucionalizadas pelas classes dominantes.

Uma outra perspectiva sobre as manifestações culturais das classes populares foi desenvolvida pelos Culturais Studies na Inglaterra. As reflexões de Raymond Williams sobre a cultura da classe operária podem nos auxiliar a refletir sobre as especificidade das organizações culturais não burguesas. Para o autor:

A classe trabalhadora, por motivo de sua posição, não produziu desde a Revolução Industrial, uma cultura no sentido mais estrito. A cultura que produziu, e que é importante assinalar, é a instituição democrática coletiva, seja nos sindicatos, no movimento cooperativo ou no partido político. A cultura da classe trabalhadora, nos estádios através dos quais vem passando, é antes social (no sentido em que criou instituições) do que individual (relativa ao trabalho intelectual ou imaginativo). Considerada no contexto da sociedade, essa cultura representa uma realização criadora notável. (WILLIAMS, 1969,p.335)

Raymond Williams observa as formações culturais como formações hegemônicas. Seguindo a trilha de Gramsci o autor pensa a cultura no plano das experiências sociais. O 
conceito de hegemonia enfatiza a dinamicidade da experiência social sem perder de vista os processos de dominação. Assim, pensar em processos hegemônicos significa refletir sobre a maneira como a cultura dominante é construída, mas também como diferentes grupos sociais disputam esta construção, como assinala o autor, há momentos contra-hegemônicos de crítica aos símbolos e valores dominantes.

A perspectiva de Williams nos oferece uma importante reflexão sobre o caráter democrático das instituições criadas pela classe operária. Podemos ampliar suas reflexões para assinalar as distinções organizativas entre as práticas culturais populares e a cultura legitimada pelas classes dominantes.

A cultura legitimada pela escola é distintiva e individualista, não é fixa, mas tende a uma maior rigidez vinculada ao padrão ocidental de racionalidade e a criação de um habitus escolar. A cultura popular, por sua vez, ao se aproximar de um saber comunitário está em constante transformação, o que ela perde em sistematicidade ganha em flexibilidade, por isso é mais inclusiva do que distintiva.

Diferente da cultura universitária, onde o neófito se adapta as convenções rígidas da epistemologia acadêmica, as práticas culturais populares estão em constante transformação com a chegada de novos sujeitos. É justamente por isso que enfatizamos as experiências em oposição às instituições. O saber acadêmico se reproduz por mecanismos institucionais como a universidade, museus e centros de pesquisa, enquanto o saber popular está atrelado à experiência dinâmica do cotidiano. Muito embora a cultura popular tenha ganhado espaço nas universidades, museus e bibliotecas, suas manifestações continuam atreladas às formas organizativas comunitárias, e em constante transformação, o movimento de institucionalização destas práticas não esgota o seu caráter dinâmico vinculado às próprias transformações no seio das comunidades em que estão inseridas.

Entretanto, é importante ressaltar que o intercruzamento de duas formas de concepção do mundo não necessariamente retira as relações assimétricas de poder dos diferentes saberes. Os diferentes capitais culturais possuem distintos valores simbólicos. A cultura universitária possibilita a aquisição de um capital cultural muito mais valorizado e legitimado socialmente do que aquele proporcionado pela cultura popular. É justamente nesta diferenciação de poder entre os tipos de práticas culturais que o projeto de extensão busca agir. Ao tomarmos a extensão como comunicação, compreendemos que a universidade se abre para multiplicidade do conhecimento, e ao compreendermos a cultura popular como dinâmica, buscamos assinalar a historicidade das práticas culturais e sua assimilação por diferentes agentes culturais. 
O projeto de extensão "Ritmos e Elementos do Maracatu de Baque Virado" se encontra neste espaço, oscila entre a experiência dinâmica e a institucionalização do conhecimento. Vive a ambiguidade entre o saber popular e o acadêmico, enfatiza um saber comunitário em constante diálogo com a instituição universitária.

\section{Conclusão: O papel da universidade}

Uma das diversas funções da universidade é a de formadora de um sistema cultural, a instituição acadêmica como produtora e transmissora de um saber é responsável também pela construção de narrativas sobre a nação. Esta construção ocorre por meio da catalogação e seleção de fatos históricos, narrativas, símbolos e patrimônios significativos que são legitimados pelo saber acadêmico.

Um desenvolvimento democrático da cultura se refere à ampliação do acesso aos bens culturais, mas também a ampliação da seleção dos bens culturais a serem legitimados pelo saber universitário, permitindo com isso, que parte significativa da população se identifique com a narrativa construída sobre a nação. Assim, a abertura da universidade a novas práticas e símbolos culturais se refere a ampliação do patrimônio valorizado e legitimado como parte da construção nacional.

A construção de uma cultura hegemônica ocorre por meio da transmissão escolar daquilo que Raymond Williams definiu como tradição seletiva. Uma tradição que é transmitida enfatizando certos valores e significados e negligenciando outros

Neste sentido podemos questionar quais são os valores e símbolos selecionados pela universidade contemporânea? Estas tradições representariam a vocação elitista na qual a universidade brasileira foi formada ou haveria possibilidade de reformulação em torno de uma vocação democrática da universidade na qual tanto vem se falando nas últimas décadas?

Ao investigar o lugar da universidade na contemporaneidade Boaventura Sousa Santos (1999) observa que esta instituição vive uma crise de legitimidade decorrente da contradição entre democratização e hierarquização dos saberes.

Destarte a extensão tem papel fundamental na transformação da vocação elitista da universidade para a vocação democrática. É justamente por meio da extensão que a universidade pode combater sua crise de legitimidade, que se funda na contradição entre uma universidade formadora e reprodutora de uma cultura elitista e o aumento da demanda das classes populares aos saberes universitários. A função tradicional de produção e reprodução de conhecimento para um grupo social restrito e homogêneo com vistas à manutenção de seu 
status social é deslocada para a produção de conhecimento para camadas muito mais amplas e heterogêneas com a função de promover sua ascensão social. Tal transformação implica na produção de novos conhecimentos e a orientação da legitimidade destes conhecimentos produzidos.

Retomando as reflexões de Boaventura Sousa Santos:

\begin{abstract}
A abertura ao outro é o sentimento profundo da democratização da universidade, uma democratização que vai muito além da democracia do acesso à universidade e da permanência nesta. Numa sociedade cuja quantidade e qualidade de vida se assenta em configurações cada vez mais complexas de saberes, a legitimidade da universidade só será cumprida quando as atividades, hoje ditas de extensão, se aprofundarem tanto que desapareçam enquanto tais e passem a ser parte integrante das atividades de investigação e ensino. (SANTOS, 1999, p.195)
\end{abstract}

Por muito tempo a universidade serviu a institucionalização da cultura dominante. Sua vocação democrática só pode se concretizar na medida em que esta instituição incluir ao seu papel de formadora de uma cultura oficial o papel de acolhedora da multiplicidade de experiências culturais.

\title{
Referências
}

ABRANTES, Terêsa Maria Otranto. Chico Science: a poesia e a dança. In Congresso Internacional da Abralic, 12, 2011, Curitiba. Anais do Congresso Internacional da ABRALIC, Curitiba, 2011, 14p.

ANDRADE, Mário de. Danças Dramáticas do Brasil, $2^{\circ}$ tomo. São Paulo: Livraria Martins Editora, 1959.

BRANDAO, Carlos Rodrigues e FAGUNDES, Maurício Cesar Vitória. Cultura popular e educação popular: expressões da proposta freireana para um sistema de educação. Educ. rev. [online]. n.61, 2016,

$<$ http://www.scielo.br/scielo.php?script=sci_arttext\&pid=S0104-

pp.89-106.

40602016000300089\&lng=en\&nrm=iso>. ISSN 0104-4060. http://dx.doi.org/10.1590/01044060.47204 .

BOURDIEU, Pierre. A economia das trocas simbólicas. São Paulo: Perspectiva, 1974.

CARVALHO, Frederico Lyra de e SANDRONI, Carlos. Controvérsias Sobre Práticas e Transformações Musicais: concepções de tradição no maracatu pernambucano. In Congresso de Iniciação Científica da UFPE - CONIC, Recife; 2011.

COSTA, F. A. Pereira da. Folk-lore Pernambucano: Subsídios para a história da poesia popular em Pernambuco. $2^{a}$ edição. Recife: CEPE, 2004. 
DELFINO, Leonara Lacerda. O Rosário dos Irmãos Escravos e Libertos: Fronteiras, Identidades e Representação do Viver e Morrer na Diáspora Atlântica. Freguesia do Pila São João Del-Rei (1772-1850). Tese (Doutorado em História), Programa de Pós-Graduação em História, Universidade Federal de Juiz de Fora, Juiz de Fora, 2015.

FREIRE, Paulo. Extensão ou comunicação. $8^{\text {a }}$ Ed. Rio de Janeiro: Paz e Terra, 1983.

LIMA, Ivaldo Marciano de França. Maracatus-Nação: Ressignificando Velhas Histórias. Recife: Edições Bagaço, 2005.

GUERRA PEIXE, César. Maracatus do Recife. Rio de Janeiro, São Paulo: Irmãos Vitale Editores, 1980.

OLIVEIRA, Jailma Maria. Rainhas, mestres e tambores: Gênero, corpo e artefatos no maracatu-nação pernambucano. Dissertação (Mestrado em Antropologia) - Programa de Pós Gradução em Antropologia, Universidade Federal de Pernambuco, Recife, 2011.

SANTOS, Boaventura Sousa. Pela Mão de Alice: O social e o político na pós-modernidade. $7^{a}$ ed. Porto: Afrontamento, 1999.

SILVA, Jéssica Helena da. A Tradição Reinventada: memórias sobre o pertencimento, o sagrado e o empoderamento feminino nos maracatus nação de Recife. Trabalho de Conclusão de Curso apresentado à Universidade Federal de Alfenas (UNIFALMG), Alfenas, 2017.

TSEZANAS, Julia Pittier. O Maracatu de Baque Virado: história e dinâmica cultural. Dissertação (Mestrado em História), Faculdade de Filosofia, Letras e Ciências Humanas, USP, São Paulo, 2010.

WILlIAMS, Raymond. Cultura e Sociedade: 1780-1950. São Paulo: Companhia Editora Nacional, 1969. 